\title{
The Impact of FDIs Flows on the Nigerien Economic Growth
}

\author{
Ousseini Hamadou \\ School of finance, Shanghai University of Finance and Economics \\ Shanghai 200083, China, \\ E-mail: diallo185@gmail.com
}

Received: May 26, 2011 Accepted: June 29, $2011 \quad$ doi:10.5430/ijfr.v2n2p16

\begin{abstract}
Niger, since the 70s has always adopted an approach that makes the IDE a major component of its development plan. It 's so, a series of measures have been taken to make the country more attractive to Foreign direct investment FDI This policy has guaranteed the country a few annual flow between the period 1970 to 2008. The aim of this paper is to try to study the impact of FDI on economic growth in Niger. Observe the literature study on FDI in Niger, however, it is also becoming important to see the between FDI and economic performance since it has not been addressed specifically yet. While it is still unclear of whether there is any relationship between FDI and economic growth in Niger, especially as regard to the causality within the relationship.

The theory and the current empirical literature on the relationship between FDI and growth have provided ambiguous results. Using VAR (Vector Autoregressive) model, this paper explores the causal relationship between FDI and economic growth for the period 1970-2008 in Niger. With in the Granger causality framework, this study finds a long-term relationship between FDI and economic growth. This finding is a long-term relationship between variables but failed to establish the direct correlation between each variable. This can be explained by the fact that low volume flows of FDI in Niger have major consequences on the economic system, particularly on employment, inflation and GDP. More, this weakness is emphasized by the insignificance of the volume of capital flows (domestic and foreign) circulating in the Nigerian economy and domestic savings.
\end{abstract}

Keywords: Foreign direct investment, Spillovers, Human capital, Total factor productivity, Opening.

\section{Introduction}

The volume of Foreign Direct Investment (FDI) towards developing countries has increased considerably during the 90s. Interest in foreign investments in developing countries is usually justified by many expectations: impact on growth, inflows of financial resources, greater exposure to international markets (exports, supplies, adaptation to standards etc.), enhanced productivity, building of local management capacity and technology transfer. Empirical studies, however, have shown mixed results as concerning developing countries.

According to the IMF manual of balance of payments, FDI is defined as a long-term investment reflecting the interest of a residing entity of the country of origin (the direct investor) in a residing entity (invested company) of another country. In other words, it is an investment aiming at securing a long-term interest in a company operating in one economy that is different from that of the investor. The investor has a clear ambition to control the management of the company. Contrary to portfolio investment, the direct investor here seeks to purchase assets for a period of time, years for instance, and is willing to influence the management of these assets even at a marginal level in the case of minority participation. Given the importance of FDIs in DCs, is an evaluation of the level of macroeconomic aggregates able to allow us to know which channels the effects of FDIs on economic growth take in Niger?

Economic growth is defined as the long-term increase of the GNP per capita within the national economy. Factors that account for growth models are: amount of capital, volume of labour, quality of labour (education), technical advancement and innovation. What are the links between FDIs and economic growth models? Are FDIs positively correlated to different factors of economic growth? This work seeks to evaluate the contribution of FDIs on economic growth in Niger.

The fundamental hypothesis we have adopted for this work to analyze the impact of foreign direct investment on economic growth in Niger from 1970 to 2008 is the following: the attraction of FDIs in Niger contribute to the expansion of markets in view of creating new jobs and facilitate economic growth. This said, can we declare that FDIs and economic growth are related? 
In order to justify the correlation between FDIs flows and the evolution of economic growth in Niger, we are going to resort to the electical theory and theories of the endogenous growth. Eclectic theory was developed by Dunning (1981, 1988) and highlights advantages a foreign firm can enjoy in using a given territory specific resources (in terms of technology marketing or organization) when these resources are complementary to its own assets.

In addition, this paper explores the causal relationship between FDI and GDP growth in Niger to help provide en empirical background for policy decision making. And find FDI is a small element in the evolution of GDP, which is consistent with the results of the analysis of shocks. Thus, if in short-term FDI have no influence on economic growth in the long term there may be a multiplier effect from a larger flow of FDI. As GDP is strongly correlated to the very long term with FDI because capital flows generated by these investments will lead to increased production and increased production and increased exports. Employing co integration VAR (Vector Autoregressive) model with annual data from period 1970-2008, the study find s the relationship for the long-run between the GDP and his explicative variables. This supportive to the government of Niger policy to attract FDI into Niger as one engine of economic growth. This work consists firstly in a presentation of the literature on FDI (empirical and theoretical studies), then a study of the actual impact of FDIs on economic growth in Niger through an analysis of the evolution of growth and flows of FDI in Niger. In this analysis, we have highlighted the overall key determinants of FDI in Niger, data and methodology, empirical result, policy conclusion and implication.

\section{Literature Review on FDI}

\subsection{Theoretical literature}

Numerous studies, both empirical and theoretical, have been devoted to FDIs by economists who have talked the issue from different perspectives. While certain studies have shown that FDIs do have positive impacts on economic growth of the host country, some others believe that FDIs are neither necessary nor sufficient to boost economic growth. Generally speaking, on this issue, we can find two main trends of thought: the first one is based on the causality between FDIs and growth and the second on FDIs spillovers in the host country. It is important to note that all these studies have serious weaknesses as concerning their statistic methods. Some authors have analyzed investment flows between different countries and group of countries such as flows between developed countries and DCs; some others have focused on reasons behind investors' decision to delocalize their production or invest in other countries while another group has tried to present different effects of FDIs on the host country.

\subsection{Empirical literature}

Various empirical studies have tried to determine the relation between these two variables. They posit that capital flows facilitate provision of capital into the economy, creating conditions of national production and economic growth under specific conditions. These conditions include technology transfer which goes hand in hand with new technics of production and TNCs' know-how; exportations for TNCs contribute to the augmentation of national production with part of it being exported. Our model is close to Zhang's (2001) idea. Here, we used temporal series proper to each country and carried out long-term causality tests based on the error correction model. The results have shown long-tem relation between FDIs and growth in Niger. In studying the relation between FDIs and economic growth in Cote d'Ivoire for the 1970-2001 periods, Loesse (2005) have found that FDIs have represented an important source of growth. All things being equal, a point increase in FDIs received in the country led to 0.01 increases in per capita GDP growth. The author affirms that investment-friendly policies implemented have contributed to the increase of FDIs flows, the overall production capacity of the economy and GDP. Carkovic and Levine (2005) fail to find an effect of FDI on growth even after accounting for dependencies on education, domestic finance, or trade. While Andreas (2006), Ndikumana and Verick (2008) and Lumbila (2005) find that FDI has a positive significant effect on economic growth, others suggest either a no significant or a negative effect of FDI on economic growth (Lougani and Razin 2003; Akinlo, 2004; Ayanwale, 2007; De Mello, 1999)

\section{Data and Methodology}

The econometric study of the relationship between FDI and economic growth in Niger is made from a VAR model (VAR) on annual basis and covers the period from 1970 to 2008 inclusive. The purpose of this econometric study is to determine potential relationships of short and long terms in the sense of Granger between variables. The VAR model is needed to detect causality between variables in the model. This model is constructed from statistics from the World Development Indicators (WDI, 2010) online Databases of the World Bank (2010) and transparency International database online (2010). We are going to present the model and we analyze the different results obtained to verify the working hypothesis. 


\subsection{Presentation of the econometric model}

The variables of this model are as follows: Foreign Direct Investment (FDI), gross domestic product (GDP), Corruption Performance Index (CPI) and Macroeconomic Instability Index (IIMACRO) which takes into account the degree of openness of the economy, variation of exchange rates and inflation. The sample considered covers 38 observations. The natural logarithm $(\log )$ of each variable was calculated on e-views to build the model in order to measure the response of a variable following a decrease or increase of another. So, throughout the model, the variables are as follows: FDI, GDP, CPI and IIMACRO.

\subsection{Model Formulation}

Let $X_{\mathrm{t}}$ with $k$ variables and $p$ lags (denoted $\operatorname{VAR}(p)$ ). A process $\operatorname{VAR}(p)$ to $k$ variables can be written in matrix form:

$X_{t}=A_{0}+A_{1} X_{t-1}+A_{2} X_{t-2}+\ldots A_{p} X_{t-p}+\varepsilon_{t}$

Where $X_{t}, A_{0}, \varepsilon_{t}$ matrices unicolonnes to $\mathrm{K}$ variables and $A_{p}$ matrix size $(\mathrm{K}, \mathrm{K}) ; \varepsilon_{t}$ is $(b b)$ the white noise of variance covariance matrix.

We can still write:

$\left.\left(1-A_{1} L-A_{2} L^{2} \ldots . A_{p} L^{p}\right) X_{t}=A_{0}+\varepsilon_{t}\right)$

$L$ is the lags operator $E X_{t}=X_{t-1}$ and more generally:

$E^{p} X_{\tau}=X_{\tau-\eta}$. Let $A(L) X_{t}=A_{0}+\sigma_{\tau}$ with $A(L)=I-S A_{l} L^{l}$

More formally we say that $X_{t} \sim \operatorname{PAR}(p)$ if and only if it is a white noise $\varepsilon_{t}\left(\sigma_{t} \sim b b(0, S \theta)\right), A_{0} E R^{N}$ and $p$ matrices $A_{1}, \ldots, A_{p}$ such as:

$X_{\tau}-S A_{l} E^{l}=A_{0}+\sigma_{\tau} \quad$ Again $A(E) X_{\tau}=A_{0}+\sigma_{0}$ where $A_{0}$ is the identity matrix $I$ and $F(L)=I-S F_{q} L^{l}$

Thus, the model can be formulated as follows:

$\log G D P=\alpha_{0}+\alpha_{1} \log F D I+\alpha_{2} \log I I M A C R O+\alpha_{3} C P I+\varepsilon_{t}$

First, we conduct the analysis of time series through statistical tests. This statistical treatment is performed before switching to the formalization of intertemporal adjustment and determination of the sensitivity of GDP compared to FDI. The order of integration of the series allows to measure levels of stationary variables. This first step is to estimate co integration relations on variables of the same order. It allows, in a second time, incorporating the specification of relationships co integration, to study the causal relationships between variables through the determination of error-correction model (ECM).

\subsection{Equations of the model}

The results of the cointegration relationship say that there exist only one relationship for the long-run between the GDP and his explicative variables.

\section{Long-Run Equation:}

The long-run is as follow:

$G D P(-1)=-14.49-0.51 F D I(-1)-0.20 \operatorname{IIMACRO}(-1)$

Short -Run Equations :( for regression table see Annex)

The short-run equations are as follow:

(1)

$\Delta \mathrm{GDP}=0.363+0.471 \Delta \mathrm{GDP}(-1)-0.037 \Delta \mathrm{GDP}(-2)-0.003 \mathrm{FDI}(-1)-0.003 \Delta \mathrm{FDI}(-2)+0.007 \mathrm{IIMACRO}(-1)-0.018 \mathrm{IIMACR}$

$\mathrm{O}(-2)-0.355 \mathrm{CPI}$ 
(2)

$\Delta \mathrm{FDI}=11.940+18.554 \Delta \mathrm{GDP}(-1)+8.086 \Delta \mathrm{GDP}(-2)+0.386 \Delta \mathrm{FDI}(-1)+0.186 \Delta \mathrm{FDI}(-2)+0.326 \Delta \mathrm{IIMACRO}(-1)-0.527 \Delta \mathrm{II}$

MACRO(-2)-14.449CPI

(3)

$\Delta \mathrm{IIMACRO}=0.889+0.985 \Delta \mathrm{GDP}(-1)-0.974 \Delta \mathrm{GDP}(-2)-0.001 \Delta \mathrm{FDI}(-1)-0.007 \Delta \mathrm{FDI}(-2)-0.955 \Delta \mathrm{IIMACRO}(-1)-0.546$

$\triangle \mathrm{IIMACRO}(-2)+0.923 \mathrm{CPI}$

Since we are dealing with a log-log model, the coefficients represent elasticity. It may be noted in the long-run equation (11) FDI has a negative (unexpected) sign and highly significant (t-ratio $\|5.64\|>2$ ) effect on the GDP, while IIMACRO has the right sign but it not significant (t-ration $\|0.38\|<2 \quad$ ).

However, in the short-run for equation (1) normalized to GDP, when the GDP in the previous year increase by $1 \%$, GDP today increase to $0.47 \%$, FDI decrease to $0.003 \%$, IIMACRO increase to $0.007 \%$ and CPI as exogenous variable decrease to $0.355 \%$. In the equation (1) excepted for the CPI all the variables are inelastic to GDP and not significant and also statically insignificant (t-ratio $<2$ ).

When the equation (2) is normalized to FDI, when the FDI in the previous year increase all the explanatory variables today has the expected sign except for IIMACRO. However excepted to GDP all the variables are not statically significant.

In the equation normalized to IIMACRO, when the IIMACRO in the previous year increase all the explanatory variables today has the expected sign. However, excepted for GDP all the variables are not statically significant.

\section{Analysis of results}

\subsection{Model Estimation}

To estimate the econometric model, the theory of co-integration has been used for this purpose. It seems efficient to test the relationships between study variables and empirically validate the results obtained after carrying out the statistical tests applied to the model. Engle and Granger (1987) presented the theory of co-integration in which a stationary linear combination can be interpreted as a relationship of long-term equilibrium between the variables studied. It is this theory which reflects the fact that if there is co-integration between a set of variables $\left(\boldsymbol{X}_{\mathrm{t}} \boldsymbol{\gamma}_{\mathrm{t}}\right)$ over time, differences of changes in these variables may exist only temporarily. Usually, the economic variables have the distinction of being integrated of order 1. They are therefore not stationary in level and have a unit root but are stationary in first difference. Before proceeding to the co-integration test developed by Johansen $(1991,1995)$, other preliminary steps are necessary to conduct such tests starting with the unit root test, determining the optimal number of delays to incorporate in the model estimate to finally determine the number of co-integrating relationships existing between the studied variables.

4.2. Unit Root Test

The lack of consensus on the relationship growth / FDI and the role of FDI as a catalyst for growth inherent difficulties that result from specific factors: technological stock available for Niger, minimum stock of human capital, institutional framework and political system. This heterogeneity of growth paths of the Nigerien economy leads to endogeneity bias and simultaneity bias in the assessment of potential bidirectional causality in specific countries. Taking account of dependent and explanatory variables with different temporal properties increases the risk of spurious results in the estimates (Greene, 1997).

To conduct an analysis based on co-integration, it should be first to check whether the series under study are integrated of order 1. To do this, we use unit root tests applied to study each series (in level and first difference). The unit root test is used as one developed by Dickey and Fuller (1981) (DF) and more specially the ADF test (Augmented Dickey Fuller) developed later. To this end, in order to give the equation to estimate and judge the stationarity of the series using the ADF test, it would be necessary to initially establish the Autoregressive process AR(1) as follows:

$Y_{t}=\mu+\varphi Y_{t-1}+U_{t}$

Where $U_{\varepsilon}$ is the white noise.

Assuming now the following equation:

$Y_{\tau}-Y_{\tau-1}=\mu-Y_{\tau-1}+\varphi Y_{\tau-1}+U_{\tau} \Rightarrow \Delta Y_{\tau}=\mu t+(\varphi-1) Y_{\tau-1}+U_{\tau}$

The DF test is then based on the estimation of the following equation: 
$\Delta Y_{t}=\mu+\gamma Y_{t-1}+U_{t}$

Under the following assumptions:

$H_{0}: \gamma=0$

$H_{1}: \gamma<0$

For an order of process $>1$, we use the ADF approach to estimate the model AR $(p)$ as follows:

$\Delta Y_{t}=\mu+\gamma Y_{t-1}+\beta_{1} \Delta Y_{t-1}+\beta_{2} \Delta Y_{t-2}+\ldots+\beta_{p-1} \Delta Y_{t-p}+U_{t}$

With $Y$ set as endogenous variable, $\mu, \gamma$, and $\beta$ the coefficients to be estimated.

This equation will be estimated under the followings assumptions:

$R_{0}: \mathcal{F}=0:$ Presence of unit root (non-stationary series)

$R_{1} \approx F \propto 0:$ The series is stationary

The decision rule is based on values in Mac-Kinnon. If the observed value exceeds the critical value given by statistics of Mac-Kinnon, we reject $\mathrm{H}_{0}$ and $\mathrm{H}_{1}$ are kept, that is to say the series is not stationary.

The tests are based the following relationships, where $\mathrm{Y}$ is the variable of interest:

$\Delta Y_{t}=s Y_{t-1}+\sum_{i=1} \beta_{i} \Delta Y_{t-i}+U_{t}$

Where $=\varphi-1,($ model without trend and constant $)$

$\Delta Y_{t}=\beta_{0}+s Y_{t-1}+\sum_{i=1}^{h} \beta_{i} \Delta Y_{t-i}+U_{t}$

(Model with constant without trend)

$\Delta Y_{t}=\beta_{0}+\delta t+s Y_{t-1}+\sum_{i=1}^{h} \beta_{i} \Delta Y_{t-i}+U_{t}$

(Model with constant and trend).

In this case we will choose $h$ so as to whiten the error $U_{t}$. The Akaike criterion is used for $h$ determination.

The assumptions are:

$F_{0}: \Sigma=0$ ou $\varphi=1 \Rightarrow$ Existence of unit root

$R_{1}=\propto 0$ aw $\varphi \propto 1 \Rightarrow$ Non-existence of unit root

Statistic: $t^{*}=s_{\text {esthwated }} /$ standard deviation $s_{\text {estinated }}{ }^{\infty}$ nonstandard normal distribution.

Decision rule: if $\mathrm{t} *<\mathrm{t}$ (tabulated) we reject $H_{\mathbb{Q}}$

The three variables are stationary in level.

4.3. Determination of the optimal number of Lag

To determine the order of a VAR model or the optimal number of lags for a VAR (p) and can use several methods. A standard procedure is to estimate all models for VAR orders $p$ ranging from 0 to a certain order $h$ fixed arbitrarily (maximum number of lags for the sample size considered, or maximum number of lags consistent with a theory or economic intuition).In practice, we set a number of delays $\mathrm{h}$ said maximum. Then we use information criteria to retain the proper order. For each model, we calculate the functions Akaike (AIC (p)) and Schwarz (SC (p)) as follows:

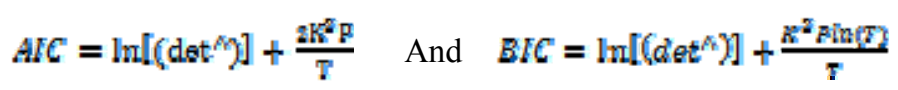

Where $\mathrm{T}$ is the number of observations, $\mathrm{K}$ the number of system variables ${ }^{\wedge}$ the variance-covariance of the estimated residuals of the model and $\ln$ the natural logarithm. The parameter estimation of VAR model is based on the number of lags or minimum order of VAR which is determined from the information criteria of Akaike (AIC) or Schwartz (SC). Using the criterion of Schwartz has given us the following results in table 2 below: Using the criterion of Schwartz has given us the following results in table 2 show that $\mathrm{P}=2$ will be the number of lags in our model.

\subsection{Co-integration Test}

In the continuity of the work of Arestis and Demetriades (1997), we opt for the approach of co-integration to analyze the role of FDI on growth, the impact of the index of macroeconomic instability and the corruption performance index on these three variables in a context of high risk countries such as Niger policy. With variables integrated in level, it is to 
identify long-run equilibrium relationships between the rate of GDP growth to FDI variables, the index of macroeconomic instability and the corruption performance index.

The co-integration test is known as that of Johansen $(1991,1995)$. Indeed, the result of the estimate gives the result of co-integration test based on the number of Eigen vectors (Eigen values) and ordered on the value of the likelihood ratio II D $\backslash$ her n $1 \cdots$ intins the following Johansen statistics:

$Q_{r}=-T \sum_{i=r+1}^{n} \ln (1-\lambda i)$

Where

T: numbers of observations $r: 0, \ldots \ldots \ldots \ldots \ldots-1$

$\lambda i$ : The largest Eigen values

$H_{0}:$ No cointegration relationship

$H_{1}$ : Presence of at least one cointegrating relationship between the series.

On the basis of critical values at the $5 \%$ and $1 \%$ that it accepts or rejects $H_{0}$. Indeed, if the LR statistic exceeds the critical data values at the $5 \%$ and $1 \%$, we reject $H_{0}$ and $H_{1}$ is accepted and it is said that there is at least one co-integrating relationship between the series studied.

The test carried out in co-integration model has three assumptions (Appendix IV, Figure2) explaining the relationship between variables.

Assumption of no relationship between the variables (none)

Since the value of the trace is great than the calculated value $(62.94>54.07)$ denotes rejection of the assumption at the $0.05 \%$ level and accept the hypothesis that exist a co-integration relationship between the variables.

Assumption at least one co-integration relationship between variables ( at most 1)

Since the value of the trace is less than the value calculated at $5 \%(34.07<35.19)$, we reject the hypothesis of existence of at least two co integrating relationships between variables. So we can conclude that there is no co-integration

Assumption at least two co-integrations relationship between variables ( at most 2)

Since the value of the trace is less than the value calculated at $5 \%(15.15<20.26)$, we reject the hypothesis of existence of at least two co-integrating relationships between variables. So we can conclude that there is no co-integration.

Thus we can conclude that there exists one co-integration relationship between the variables.

\subsection{The Impulse Response analysis}

Consider a process $\left\{\mathcal{X}_{\mathrm{\tau}}, \varepsilon \in Z\right.$ \} with satisfactory representation $\operatorname{VAR}(p)$ as follows:

$F(L) X_{t}=X_{t}-F_{1} X_{t-1}-F_{2} X_{t-2}-\ldots-F_{p} X_{t-p}$

Assume that the innovations are i.d, $\sigma_{t} \sim b b(0, S e)$ and one has $T+p$ achievements of this process. Assume further that $F_{i}$ parameters are known, but the same analysis can be conducted when there has only estimators of these parameters. Then we can express the general idea of evolution of a component $\mathcal{X}_{2}, t$ which occurs after a pulse on $\mathcal{X}_{j}, t$ on the period ${ }^{T}$; assuming all other variables is constant for ${ }^{t} \mathrm{~S} T$. Thus the impulse response analysis or impact analysis is to study or to measure the impact or the effect of the variation of the innovation variables.

The analysis reveals that impulse responses of the FDI to shock of the GDP are positive in the early and in middle period tend to be negative and thereafter become positive but with a low amplitude. While the impulse responses of the FDI to shock of the IIMACRO are low and negative. However the flows of FDI have a positive influence on the IIMACRO in the way it contributes to decrease the rate of IIMACRO.

The responses of the GDP response to shocks of FDI are high and positive. The responses of the GDP responses to shocks IIMACRO are negative in the early and after tend toward zero. These mean that in the early the GDP is influenced by the flows of FDI.

The responses of the IIMACRO responses to shocks of FDI and to GDP are both positive but very low in the early and tend toward zero. This means that the rate of IIMACRO has a small influence on the FDI and GDP. (Appendix 2 figure 4). 


\subsection{Decomposition of the variance}

The study of the variance decomposition allows complete analysis of shocks. The objective is to calculate the contribution of each innovation to the variance of the forecast error. The results of variance decomposition show that the variance of forecasting FDI is due to $68 \%$ of its own innovations, $29.20 \%$ of those of the GDP and $2.79 \%$ of those of IIMACRO . The variance of GDP forecast is due to $86.10 \%$ of its own innovations, $13.82 \%$ of those of the FDI and $0.07 \%$ of those of IIMACRO . The variance of IIMACRO forecast is due to $91.35 \%$ of its own innovations, $1.87 \%$ of those of the FDI and $6.77 \%$ of those of GDP.

In summing up, the results say FDI is a small element in the evolution of GDP, which is consistent with the results of the analysis of shocks. Thus, if in short-term FDI have no influence on economic growth in the long term there may be a multiplier effect from a larger flow of FDI. As GDP is strongly correlated to the very long term with FDI because capital flows generated by these investments will lead to increased production and increased production and increased exports.

\subsection{Granger causality test}

The test of Granger causality is used to determine which type is the correlation of the indicator with the reference series. It involves comparing the average squared errors (EMC) to predict the next value of a series using two alternative forecasting methods: one using only shifts the series to predict and the second using shifts the series to be set and those of the series that we test causality. For linear models, Granger causality is rejected if:

$$
\operatorname{ECM}\left[\widehat{E}\left(X_{t+s} / X_{t}, X_{t-1}, \ldots\right)\right]=\operatorname{ECM}\left[\widehat{E}\left(X_{t+S} / X_{t}, X_{t-1} \ldots, Y_{t}, Y_{t-1}, \ldots\right]\right.
$$

Where $\mathrm{Y}$ is the variable that we test the causal $\mathrm{X}$. The question is whether the variable $\mathrm{X}$ "cause" or not the variable $\mathrm{Y}$. They say that the variable $\mathrm{x}$ because the sense of Granger variable $\mathrm{Y}$ if and only if knowledge of the past of $\mathrm{X}$ improves the forecast of yet any horizon.

If the null hypothesis is rejected, the test will say that the series will cause by Granger X, that is to say, it contains information that can predict the movements of $X$, and vice versa performing the same test in reverse. If one seeks to construct an indicator to predict the movement of a reference series, hopefully ideally be determined by this test that the change in the indicator above those of the reference series and not the other, so that Granger causality exists only in the expected direction.

\section{Further Analysis of the Empirical Results}

The VAR model used in the work is to provide efficient systems of interrelated time series and to analyze the impact of FDI on economic growth. The VAR approach requires structural modeling by modeling each endogenous variable in the system as a function of lagged values of all other endogenous variables in the system based on the results obtained. The analysis result of the model is focused on testing causality Granger.

\subsection{Empirical results of the model}

The analysis of causality in Granger sense, are usually based on a specification autoregressive (VAR) process data generator. This applies especially to the many studies of causation between FDI and growth at the macroeconomic level.

The variable FDI and economic growth have the advantage of being present in a natural order starting with linear constraints. This new characterization facilitates a sequential testing procedure which can often lead to conclusions about causality (in Granger sense).

The test of Granger causality analysis applied to multivariate autoregressive determines whether an endogenous variable could be considered an exogenous variable. It also shows the degree of relevance of some variables to improve the prognosis of some others.

The results of this test, the equations of FDI reveals the importance of lagged values of GDP and IIMACRO for improving forecasts of FDI generated by the model. In other words, the lagged values of these variables cause the present value of FDI. The same scenario for the equations of GDP, lagged values of FDI and IIMACRO values could explain the present GDP, while it is different for variable IIMACRO, might be considered an exogenous variable. Table 4 shows that there is no relationship Granger causality between all the variables studied. Unlike some studies in the above work and have been made for some developing countries, FDI does not cause economic growth (in the sense of Granger) in the case of Niger for the period 1970 to 2008. GDP real growth rate included in the work to reflect changes in economic growth does not cause as FDI (since F-stat=3.82and Prob=0.03). 
As used statistical theory requires stationarity of data, we modeled the natural logarithm of each of these variables differentiated once or twice as needed. The vector of these variables and selected is: $X_{t}=\left[(1-L) \ln \left(F D I_{t}\right),(1-L)^{2 \ln }\left(\right.\right.$ IIMACRO $\left.\left._{t}\right),(1-L)^{2} \ln \left(G D P_{t}\right)\right]$

Therefore, variables InFDI, InGDP and InIIMACRO designate the processed forms of these variables as they appear in the vector $X_{t}$ and the causal relationships are identified (in the strict sense) be interpreted as linking these transformed variables. Therefore, FDI should be interpreted as the rate of growth this year, while GDP or its growth rate and IIMACRO correspond to changes in their respective growth rates. It is also noteworthy that the variable IIMACRO does not directly affect GDP in the model but it has an indirect influence on it since it causes the FDI. So, this influence through the channels of transmission of FDI is regarded as an effective vehicle for catalyzing economic growth.

\section{Policy Implication}

In order to optimize the impact of the relationship between FDI and economic growth in Niger, some policies implication can be considered for further generating economic growth and attracting FDI in Niger: Managing macroeconomic stability to achieve sustainable economic growth. Improving investment climate and increasing absorption capacity, rational exploitation of mineral resources in creating value-added exploration of other sources of growth (tourism, livestock by-products, crafts...).

\section{Conclusion}

Using Co-integration VAR (Vector Autoregressive) Model, this study explored the relationship between FDI and economic growth impact to the period 1970-2008; finding FDI is a small element in the evolution of GDP, which is consistent with the results of the analysis of shocks. Thus, if in short-term FDI have no influence on economic growth in the long term there may be a multiplier effect from a larger flow of FDI. As GDP is strongly correlated to the very long term with FDI because capital flows generated by these investments will lead to increased production and increased production and increased exports.

In the case of Niger, this study opt for the approach of co-integration relationship to analyze the role of FDI on growth, the impact of the index of macroeconomic instability and the corruption performance index on these three variables in a context of high risk countries such as Niger policy. With variables integrated in level, it is to identify long-run equilibrium relationships between the rate of GDP growth to FDI variables, the index of macroeconomic instability and the corruption performance index.

For the future research , the study could be expanded to the robustness of these results deserve to be verified by including in the regressions a breakdown of FDI by their nature and objectives and the different economic sectors in Niger.

\section{References}

Backer,K.D.E, (2002),Does Foreign Direct Investment Crowd Out Domestic Entrepreneurship" Vlerick working paper , No.14.

Baldwin, R.E., Braconier, H. \& Forslid R. (1999), Multinationals, Endogenous Growth and Technological Spillovers: Theory and Evidence. Discussion Paper $\mathrm{N}^{\circ} 2155$, Center for Economic Policy Research, London, UK.

Baliamoune, M. (2002), Assessing the Impact of One Aspect of Globalization on Economic Growth in Africa, WIDER Discussion Paper No. 2002/91, World Institute for Development Economics Research of the United Nations University, Helsinki.

Bergstrand, Jeffrey H. \& Peter Egger. (2004) A Theoretical and Empirical Model of International Trade and Foreign Direct Investment with Outsourcing: Part I, Developed Countries, Mimeo.

CHARVIN, Robert, l'investissement international et le droit au développement, Edition ～L'Harmattan, 2002, 203 pages.

Chen, C., Chang, L. \& Zhang, Y. (1995). The role of foreign direct Investment in China's post-1978 economic development, World Development, 23(24):691-703, doi:10.1016/0305-750X(94)00143-M, http://dx.doi.org/10.1016/0305-750X(94)00143-M

CNUCED (2005), World Investment Report, 1999-2005.

De Mello, L.R. (1997), Foreign Direct Investment in Developing Countries and Growth: A Selective Survey, Journal of Development Studies, 34, 1-34, doi:10.1080/00220389708422501, http://dx.doi.org/10.1080/00220389708422501

De Mello, L.R. (1999), Foreign Direct Investment-led Growth: Evidence from Time Series and Panel Data, Oxford Economic Papers, 51, 133-151, doi:10.1093/oep/51.1.133, http://dx.doi.org/10.1093/oep/51.1.133 
Dunning, J. H. (2001), The Eclectic (OLI) Paradigm of International Production: Past, Present and Future, International Journal of Economics of Business, Vol. 8, No. 2, doi:10.1080/13571510110051441, http://dx.doi.org/10.1080/13571510110051441

Dunning, J. H., (1998), The Eclectic Paradigm of International Production: A Restatement. and Some Possible Extensions , Journal of International Business Studies-Spring, 1998, 3-4.

Merlevede, Bruno et Koen Schoors (2004), Determinants of Foreign Direct Investment in Transition Economies, unpublished

R Development Core Team (2008). R: A Language and Environment for Statistical Computing. Vienna, Austria: R Foundation for Statistical Computing. ISBN3-900051-07-0.

STIGLITZ, Joseph E., Principes d'économie moderne, nouveaux horizons, De Boeck Université, 2000,939 pages.

Wang, Z. Q. \& Swain, N., (1995), The Determinants of Foreign Direct Investments InTransforming Economics: Empirical Evidence from Hungary and China. Weltwirtschaftliches Archive. 131: 358-82, doi:10.1007/BF02707440, http://dx.doi.org/10.1007/BF02707440

Xiaoying, L. \& Xiaming, L., (2005), Foreign Direct Investment and Economic Growth: An Increasingly Endogenous Relationship, World Development, vol. 33, Issue 3.

Zhang, K. H. (2001), Does foreign Direct Investment promote Economic Growth? Evidence-from East Asia and Latin America, Contemporary Economic Policy (ISSN 1074-)

Table 1. Unit Root Test

\begin{tabular}{|c|l|l|l|l|l|l|}
\hline \multirow{2}{*}{ variables } & \multicolumn{2}{|c|}{ constant } & \multicolumn{2}{c|}{ Constant\& Trend } & \multicolumn{2}{c|}{ None } \\
\cline { 2 - 7 } & levels & $1 * 1_{\Delta}$ & levels & 1 levels & $1^{* *_{\Delta}}$ \\
\hline GDP & -1.9891 & $-4.0623^{* *}$ & $-2.8336^{* *}$ & $-4.0276^{* *}$ & 0.4780 & $-4.0946^{* *}$ \\
\hline FDI & $-4.5456^{* *}$ & $-9.7070^{* *}$ & $-4.6072^{* *}$ & $-9.5647^{* *}$ & $-3.5743^{* *}$ & $-9.8407^{* *}$ \\
\hline IIMACRO & $-4.4252^{* *}$ & $-8.2148^{* *}$ & $-4.4451^{* *}$ & $-8.0861^{* *}$ & $-0.7317^{* *}$ & $-8.3378^{* *}$ \\
\hline
\end{tabular}

Notes:

1. using critical values by MacKinnon, 1996

2. *indicates stationarity at $5 \%$ level and $* *$ indicates stationarity at $1 \%$ level

3. Lag length automatically chosen (by Eviews 6) using Schwarz Information Criterion (SIC)

Table 2. Choice of the Optimal Lags

\begin{tabular}{|c|c|c|c|}
\hline $\begin{array}{c}\text { Criterion } \\
\text { information }\end{array}$ & $\mathrm{P}=2$ & $\mathrm{P}=4$ & $\mathrm{P}=6$ \\
\hline $\mathrm{SC}$ & 9.40495 & 10.85699 & 11.52996 \\
\hline
\end{tabular}


Table3. Cointegrating Regression

\begin{tabular}{cc}
\hline \hline Cointegrating Eq: & CointEq1 \\
\hline \hline GDP(-1) & 1.000000 \\
FDI(-1) & -0.517177 \\
& $(0.09167)$ \\
& {$[-5.64168]$} \\
IIMACRO(-1) & -0.208853 \\
& $(0.54088)$ \\
& {$[-0.38614]$} \\
C & -14.49010 \\
\hline \hline
\end{tabular}

Note: Standard errors are in parenthesis and t-ratios are in brackets.

Table 4. Granger Causality Test

Pairwise Granger Causality Tests

Date: 09/26/10 Time: 19:26

Sample: 19702008

Lags: 2

\begin{tabular}{lccc}
\hline \hline Null Hypothesis: & Obs & F-Statistic & Prob. \\
\hline \hline FDI does not Granger Cause GDP & 37 & 0.32333 & 0.7261 \\
GDP does not Granger Cause FDI & & 3.82900 & 0.0323 \\
\hline \hline CPI does not Granger Cause GDP & 37 & 3.47570 & 0.0431 \\
GDP does not Granger Cause CPI & & 0.06100 & 0.9409 \\
\hline \hline IIMACRO does not Granger Cause GDP & 37 & 3.48114 & 0.0429 \\
GDP does not Granger Cause IIMACRO & & 1.70656 & 0.1976 \\
\hline \hline CPI does not Granger Cause FDI & 37 & 1.33682 & 0.2770 \\
FDI does not Granger Cause CPI & & 0.45450 & 0.6388 \\
\hline \hline IIMACRO does not Granger Cause FDI & 37 & 0.28359 & 0.7550 \\
FDI does not Granger Cause IIMACRO & & 0.35996 & 0.7005 \\
\hline \hline IIMACRO does not Granger Cause CPI & 37 & 0.17009 & 0.8443 \\
CPI does not Granger Cause IIMACRO & & 0.44253 & 0.6463 \\
\hline \hline
\end{tabular}

Pairwise Granger Causality Tests

Date: $09 / 25 / 10$ Time: 12:37

Sample: 19702008

Lags: 2

$\underline{\text { Null Hypothesis: }}=\underline{\underline{\text { Obs }}}=$




\begin{tabular}{lccc} 
GDP does not Granger Cause FDI & 37 & 3.82900 & 0.0323 \\
FDI does not Granger Cause GDP & & 0.32333 & 0.7261 \\
\hline \hline IIMACRO does not Granger Cause FDI & 37 & 0.28359 & 0.7550 \\
FDI does not Granger Cause IIMACRO & & 0.35996 & 0.7005 \\
\hline \hline CPI does not Granger Cause FDI & 37 & 1.33682 & 0.2770 \\
FDI does not Granger Cause CPI & & 0.45450 & 0.6388 \\
\hline \hline IIMACRO does not Granger Cause GDP & 37 & 3.48114 & 0.0429 \\
GDP does not Granger Cause IIMACRO & & 1.70656 & 0.1976 \\
\hline \hline CPI does not Granger Cause GDP & 37 & 3.47570 & 0.0431 \\
GDP does not Granger Cause CPI & & 0.06100 & 0.9409 \\
\hline \hline CPI does not Granger Cause IIMACRO & 37 & 0.44253 & 0.6463 \\
IIMACRO does not Granger Cause CPI & & 0.17009 & 0.8443
\end{tabular}

Pairwise Granger Causality Tests

Date: 09/25/10 Time: 12:56

Sample: 19702008

Lags: 2

\begin{tabular}{lcccc}
\hline \hline Null Hypothesis: & Obs & F-Statistic & Prob. \\
\hline \hline FDI does not Granger Cause GDP & 37 & $\begin{array}{l}0.32333 \\
3.82900\end{array}$ & $\begin{array}{l}0.7261 \\
0.0323\end{array}$ \\
GDP does not Granger Cause FDI & & & & 0.0429 \\
\hline \hline IIMACRO does not Granger Cause GDP & \multirow{2}{*}{37} & 3.48114 & 0.1976 \\
GDP does not Granger Cause IIMACRO & & 1.70656 & 0.7550 \\
\hline \hline IIMACRO does not Granger Cause FDI & \multirow{2}{*}{37} & 0.28359 & 0.7005 \\
FDI does not Granger Cause IIMACRO & & 0.35996 & 0.70 \\
\hline \hline
\end{tabular}

